\title{
Exploring direct costs of primary hip and knee arthroplasties healthcare- associated infections: A retrospective study
}

\author{
João Moura ${ }^{\mathrm{a}}$, \\ Pilar Baylina ${ }^{b}$, J \\ oão Logarinhoc, \\ Filipe Conceiçãoc, \\ Ricardo São Simão ${ }^{d}$ \\ Carlos Alves ${ }^{\mathrm{e}}$
}

${ }^{a}$ Associação de Politécnicos do Norte, Instituto Politécnico do Porto, Porto, Portugal; 'b Escola Superior de Saúde do Porto, Instituto Politécnico do Porto, Porto, Portugal; ' ${ }^{C}$ AG Cirurgia, Centro Hospitalar de São João EPE, Porto, Portugal; ${ }^{d}$ Serviço de Ortopedia, Centro Hospitalar de São João EPE, Porto, Portugal; 'Unidade de Prevenção e Controlo de Infeção e Resistências aos Antimicrobianos, Centro Hospitalar de São João EPE, Porto, Portugal

\begin{abstract}
Hip or knee arthroplasty healthcare-associated infections (HAl) are a public health problem that induces the increase of morbidity and mortality rates and poses an economic problem with significant impact on hospitals budget. The infection rate in primary hip and knee arthroplasties range between $1.5 \%$ and $2.5 \%$, and is considered one of the main reasons for surgeries non-effectiveness. A retrospective study was carried out in S. João Hospital Center, EPE (CHSJ) to calculate HAI rate in primary hip and knee arthroplasties, and to analyse their direct costs, for a better understanding of their economic impact. Four hundred and eighty seven arthroplasties were studied and infection was noticed in 11 cases: 3 after hip and 8 after knee arthroplasties. Data collected from infected patients-related costs were compared with the average cost of non-infected patients (standard). An incidence rate of $2.17 \%$ for hip arthroplasties and $2.25 \%$ for knee arthroplasties was found. Results showed that patients with infection remained in hospital 7.45 times longer than uninfected patients and incurred hospital costs almost 3.8 times higher. This work shows how important is the quantification of additional HAl costs to allow hospital managers to weigh the cost/benefit ratio and better justify investments in HAl prevention and control programmes.
\end{abstract}

\author{
KEYWORDS \\ Hip and knee arthroplasties; \\ healthcare-associated \\ infections; surgical site \\ infections; length of stay; \\ costs
}

\section{Introduction}

Healthcare-associated infections (HAI) became one of the most common adverse events associated with health systems, through an adverse impact on hospital expenses and compromising healthcare quality and effectiveness.

At international level, health systems have been facing a continuous rise in expenditures, and Portugal followed this trend, currently representing $26 \%$ of state expenditure (2006 figures) and 10.6\% of Gross Domestic Product (GDP) [1].

The economic costs related with HAI can be noticed through the increase at the average length of stay, usage of antibiotics and other drugs, employment of more diagnostic and therapeutic means and resources, in addition to other social and intangible costs. These excesses significantly increase hospital expenses, which, in turn, have increasingly scarce resources. Additionally, consuming resources on treating this type of infections (again, potentially preventable) promote a decrease of available resources to allocate to other areas of care. Therefore, the importance of accurate economic assessment of HAI costs is even more significant since quantifying the additional costs associated with HAI, will support hospital managers in the development of health policies dedicated to infection prevention and control, thus reducing their impact [2].

The advances made in healthcare during the last decades have led to a significant increase in the average life expectancy, especially in industrialized countries [3]. In accordance, the promotion of active aging is a growing challenge for society and health systems to ensure that elderly population lives in a healthy, autonomous and independent way as long as possible [4]. However, and despite all efforts, aging of population is still associated with the prevalence of degenerative diseases, such as those associated with hip and knee joints $[3,5]$.

As a result, hip and knee arthroplasties are currently the most common surgical procedures and, when successful, significantly improving patient's quality of life. However, the large volume of arthroplasties performed have to be considered, as well as the increasing risk of prosthetic joint infection (between $1.5 \%$ and $2.5 \%$ of all knee and hip arthroplasties, tend to become infected) [6-11]. This is considered to be one of the most serious complications that can occur after an arthroplasty.

This said, we are faced with an emerging issue and hospital infection's rate is currently assumed as one 
Table 1. Variables and costs considered to direct cost determination.

\begin{tabular}{|c|c|}
\hline Variable & Cost \\
\hline Hospitalization daily costs (Average daily cost) & $182.34 €$ \\
\hline New Hip prosthesis costs (in the cases where there was replacement of the initial prosthesis) (kit's price) & $1320.80 €$ \\
\hline New Knee prosthesis costs (in the cases where there was replacement of the initial prosthesis) (kit's price) & $1000.00 €$ \\
\hline Intervention costs (includes fixed staff costs, External Service Provision and depreciations) (Average cost) & $654.98 €$ \\
\hline Cost of revision materials (in cases where there was revision with replacement of a prosthesis component) & * \\
\hline Cost of materials for clinical consumption (with the exception of the prosthesis) used for to the patient during the re-hospitalization episode & ** \\
\hline Medication costs; & ** \\
\hline Complementary Diagnostic and Therapeutic Means (CDTMs) (Average daily cost per patient) & $10.19 €$ \\
\hline Orthopaedic follow-up cost due to infection (Average cost) & $28.79 €$ \\
\hline
\end{tabular}

of the indicators of clinical effectiveness and patient safety $[12,13]$.

Naturally, this problem is also of increasing importance in terms of healthcare management in Portugal, but, despite its importance being widely recognized, Portuguese studies about HAI costs are rare.

The main objectives of this study were: to identify the infection rate in primary hip and knee arthroplasties, to determine the intrinsic risk factors (comorbidities) in the infected patients and, above all, to analyse the direct costs related to surgical treatment, by comparing the cost associated with infected patients with the average cost of the non-infected patients (standard), in order to better understand their economic impact in health systems.

\section{Methodology}

An observational, analytical and retrospective study was carried out in a group of patients hospitalized in the Orthopaedic Department from de S. João Hospital Center, EPE (CHSJ), who underwent hip or knee arthroplasties within a two years' period, between May 2014 and May 2016. In this case study, the average costs for uninfected primary arthroplasty from all patients (standard cost) were compared with the average costs of infected primary arthroplasty (infected patients).

Data were collected using the computer software HSJ.IEG - Epidemiological and Management Information. A list of all primary hip and knee arthroplasties performed in the orthopaedic department during the study period was consulted using ICD-9 procedure codes: 81.51 for total hip replacement, 81.52 for partial hip replacement and 81.54 for total knee replacement. From this research, electronical clinical records (with data encryption) off all patients who underwent hip or knee arthroplasties during the study period were obtained.

Using the software SClinico, and with the support of an orthopaedic specialist, all the electronical clinical records of all these patients were analysed. Infected patients were identified through records that showed re-interventions and/or re-hospitalizations following primary arthroplasty.

To obtain the direct costs of infected patients, the variables presented in Table 1 were considered.
After data collection, a descriptive statistical analysis was performed in order to understand the data distribution and to compare the data obtained for infected patients with standard data.

This study was approved by the ethical commission of the S. João Hospital Center, EPE (CHSJ), and data confidentiality and anonymity of participants were ensured using a codification system.

\section{Results}

The study's sample consisted of a total of 487 arthroplasties (138 hip arthroplasties and 349 knee arthroplasties), mainly constituted by female patients (73.3\%). The patients' age ranged from 29 to 83 years, with a mean age of 67.8 years (67.9 for the hip and 67.8 for the knee). Regarding the 487 surgical procedures performed, 11 infected arthroplasties were detected: 3 of them occurred after primary hip arthroplasty and 8 after primary knee arthroplasty.

From these results, incidence rates of infection of $2.17 \%$ for hip arthroplasties and $2.25 \%$ for knee arthroplasties, were obtained. Both of these values are similar to those reported in most international studies. Concerning age, the patients that developed infections were between 46 and 83 years old, and the age groups most affected were the 60-69 and 80-89 groups. Intrinsic risk factors like obesity, diabetes or hypertension, have a big influence on the development of infection since most of the patients are below optimal health status. These factors, also called comorbidities, if not controlled, may contribute to the onset of an infection. In this study, despite diabetes being present in two infected patients, Obesity was present in three of the infected patients and hypertension in five. However, it was not possible to establish the relation cause-effect between the presence of comorbidities and the occurrence of infections.

\section{Length of stay: infected patient vs. uninfected patient}

The length of stay is one of the most discrepant factors when comparing the non-infected patients with the infected patients. In the overall analysis of our sample, the length of stay of infected patients was significantly 
Table 2. Average cost of patients who underwent primary arthroplasty (standard cost).

\begin{tabular}{|c|c|c|c|c|c|c|c|c|}
\hline $\begin{array}{l}\text { Hospitalization } \\
\text { costs }(€)\end{array}$ & $\begin{array}{l}\text { Prosthesis } \\
\text { cost }(€)\end{array}$ & $\begin{array}{l}\text { Intervention } \\
\text { costs }(€)\end{array}$ & $\begin{array}{l}\text { Medication } \\
(€)\end{array}$ & $\begin{array}{c}\text { Material for } \\
\text { clinical } \\
\text { consumption }(€)\end{array}$ & $\begin{array}{l}\text { Average cost } \\
\text { for CDTMs } \\
\text { per patient } \\
(€)\end{array}$ & $\begin{array}{c}\text { Total } \\
\text { hospitalization cost } \\
\text { without } \\
\text { complications }(€)\end{array}$ & $\begin{array}{l}\text { Costs of } \\
\text { orthopeadic } \\
\text { follow-up visits } \\
(€)\end{array}$ & $\begin{array}{l}\text { Total direct } \\
\text { cost per } \\
\text { patient }(€)\end{array}$ \\
\hline 1177.16 & 1090.90 & 654.98 & 45.99 & 209.98 & 65.79 & 3244.80 & 166.98 & 3411.78 \\
\hline
\end{tabular}

higher than for those not infected. The uninfected patient (standard patient) had 6.46 days as a mean length of stay, while an infected patient remained in the hospital 41.7 more days (mean). Therefore, the length of stay was, on average, 7.45 times higher in infected patients, which reveals values much higher than those found in the literature review.

\section{HAl direct costs:}

In order to evaluate and quantify HAI associated costs, a comparison between the average of the 487 primary arthroplasty performed (which is referred as the standard cost) and the average of infected patients' costs was made. Based on all the variables that were analysed, the standard cost of a patient undergoing primary arthroplasty of the hip or knee was calculated first (Table 2).

From the sum of the first six items of Table 1, the cost of hospitalization without complications was obtained (Column 7). However, patients who underwent primary arthroplasty had, on average, 5.8 follow-up visits. For infected patients, data is shown in Table 3.

Since all the infected patients had the first hospitalization without complications and a subsequent hospitalization due to the appearance of the infection, it was decided to show the costs of the first hospitalization, to compare them with those obtained for the standard patient, and then add to the value obtained the additional costs associated with the development of the infection: costs of re-hospitalization and followup visits. In this way, the total cost for each of the infected patients was obtained (Table 2).

Table 3. Costs comparison between infected and uninfected patients.

\begin{tabular}{llccc}
\hline Patient & $\begin{array}{c}\text { Infected } \\
\text { Prosthesis }\end{array}$ & $\begin{array}{c}\text { Primary } \\
\text { arthroplasty } \\
\text { costs }(€)\end{array}$ & $\begin{array}{c}\text { Additional } \\
\text { infection } \\
\text { costs }(€)\end{array}$ & $\begin{array}{c}\text { Total cost per } \\
\text { infected } \\
\text { patient }(€)\end{array}$ \\
\hline A & Knee & 2985.66 & 2783.07 & 5768.73 \\
B & Knee & 2144.00 & $11,778.03$ & $13,922.03$ \\
C & Hip & 4824.68 & 9127.53 & $13,952.21$ \\
D & Hip & 3130.05 & $33,058.42$ & $36,188.47$ \\
E & Knee & 3029.12 & 3637.70 & 6666.82 \\
F & Hip & 4215.63 & 4758.44 & 8974.07 \\
G & Knee & 2896.64 & 9495.19 & $12,391.83$ \\
H & Knee & $\mathbf{6 6 4 5 . 4 9}{ }^{\text {a }}$ & $17,185.93$ & $\mathbf{2 3 , 8 3 1 . 4 2 *}$ \\
I & Knee & 3137.99 & $12,577.58$ & $15,715.57$ \\
& Knee & 3.095 & 2743.04 & 5838.04 \\
Average & cost per infected patient $(€):$ & & $\mathbf{1 3 , 0 2 2 . 6 5}$ \\
\hline
\end{tabular}

a Patient $\mathrm{H}$ had two hospitalizations in which he underwent arthroplasty of the right knee and left knee respectively. He was re-hospitalized due to an infection of the right knee prosthesis and during the hospitalization he also acquired an infection on the left knee prosthesis. Therefore, it was agreed to add the costs of the two initial hospitalizations and sum it to the additional cost caused by the re-hospitalization, where he acquired the infection in both prostheses. Therefore, the $\mathbf{2 3 . 8 3 1 . 4 2 €}$ correspond to the total cost of two infected arthroplasties.
Considering the patient $\mathrm{H}$ specificity, the mean cost per infected patient resulted from the addition of the total costs of the infected patients, but instead of dividing by 10 ( $\mathrm{n}^{\circ}$ re-hospitalizations) was divided by 11 (number of arthroplasties infected).

According to the results obtained for the cost of an infected patient's treatment, on average, it was 3.8 times higher than a standard patient's treatment.

Taking into account that the standard mean cost for uncomplicated primary arthroplasty was $3411.78 €$ and patients who acquired an infection had a total of 11 hospitalizations in which they underwent primary arthroplasty, the hospital would be expected to spend approximately $37,529.58 €$, if no infection had been acquired. However, the hospital spent on the 10 readmissions that corresponded to 11 infected arthroplasties, a total of $143,249.19 €$, which represents a surplus cost of 105,719.61 $€$.

Based on the extra costs, the opportunity cost of performing primary arthroplasty was also calculated. That is, if no infection had been acquired and the primary arthroplasty had occurred without complications, approximately 31 more primary hip or knee arthroplasties could have been performed in this period.

\section{Discussion}

As shown in this study the incidence rates of infection are similar to those reported in most international studies. According to Taylor et al. [10], between 1.5\% and $2.5 \%$ of all knee and hip arthroplasties tend to become infected. Related to common comorbidities, and according to a European study conducted by Tumbarello et al. [14], the most common comorbidities among patients with HAI were diabetes (27.8\%), neoplasms (27.8\%) and malignant haematological disease (22.2\%). In this study, despite diabetes being present in two infected patients, two others comorbidities stood out from all others, due to their incidence on the infected patients: obesity and hypertension.

The length of stay is one of the most discrepant factor comparing with literature. According to Plowman [15], the infected patients showed the length of stay 2.5 times higher when compared to patients who did not develop any infection. However, in this study, it was, on average, 7.45 times higher in infected patients, which reveals values much higher than those found in the literature review. This value may be due to the relatively small number of infected patients present in the sample, and to the fact that some of them have shown 
extremely high length of stay. It is also important to highlight the burden of the length of stay on the cost of the infected patients. Some studies reported the length of stay as the factor with the highest cost for an infected patient [11,16-18] and in this study, this is also verified. We found that, on average, $61.74 \%$ of the costs of the infected patients were due to the costs of re-hospitalization stay.

Regarding the direct costs with SSI, it is worth mentioning that, compared to other studies, costs were slightly higher. However, the cost analysis carried out by this study was a comprehensively more detailed than most of the literature consulted on this subject, which is considered to be an advantage. Differently from the majority of the published studies, not only the costs of hospitalization and re-hospitalization of the infected patients were considered but also the costs of subsequent orthopaedic consultations were included. In this way, the total direct cost of the patient with SSI was obtained, which is considered to be a more complete analysis of the SSI costs related to hip and knee arthroplasties.

\section{Limitations}

Throughout the study, some difficulties occurred, namely in the calculation of the direct costs to the hospital due to SSI. This means that it was not always possible to obtain the direct costs, so certain items were calculated with the average values of the CHSJ records.

The temporal limitation of data collection is another relevant issue. As stated before, all patients undergoing primary hip or knee arthroplasty between May 2014 and May 2016 were considered, and it is noticed that a 12-month follow-up of the patient after surgery is usually performed. However, by the end of this research, many patients had not yet been followed up therefore, some infections may occur on these patients beyond the period considered in this study.

\section{Conclusions}

In this study, it was possible to identify and quantify hip and knee arthroplasties infection rates and their direct cost. The results, obtained by comparing the costs of the length of stay, surgical interventions, antibiotics used, materials of clinical consumption and complementary diagnostic and therapeutic means in the infected and non-infected patients, are in accordance with the literature review.

In Portugal, there are few studies about HAI costs and, as mentioned previously, this research was intended to be a contribution in an area where studies are scarce and at the same time contribute to demystify the idea that health care related costs are not feasible to evaluate. The results of this study are also very important to increase awareness about HAI costs, supported by an accurate economic assessment. In addition, quantifying costs associated with HAI, will allow hospital managers from S. João Hospital Center to weigh the cost/benefit ratio and better justify investments in HAI prevention, especially since it is known that a large number of Infections could be prevented.

New studies to determine the HAI costs using larger samples and longer follow-up times should be developed, so that it may be possible to achieve a more rigorous evaluation of the economic impact of HAI in health systems. This knowledge will contribute to better know the HAI economic problem to support the decision-making process, and help healthcare managers all over the world to better decide about new investments in HAI prevention and control programmes based on supported cost-benefits analysis. 


\section{References}

[1] Borges CM, Ramalho $R$, Bajanca $M$, et al. Implementação de um sistema de custeio por actividades nos hospitais do SNS. Revista Portuguesa de Saúde Pública. 2010;9:141-160.

[2] Fukuda H, Lee J, Imanaka Y. Variations in analytical methodology for estimating costs of hospital-acquired infections: a systematic review. J Hospital Infect. 2011;77:93-105.

[3] Widmer AF. New developments in diagnosis and treatment of infection in orthopedic implants. Clin Infect Dis. 2001;33:S94-S106.

[4] DGS. Programa Nacional para a Saúde de Pessoas Idosas. Direção Geral de Saúde; 2004.

[5] Schairer WW, Sing DC, Vail TP, et al. Causes and frequency of unplanned hospital readmission after total hip arthroplasty. Clin Orthopaed Related Res. 2014;472:464-470.

[6] Fonseca F. Infecção em artroplastias do joelho. Revista Portuguesa de Ortopedia e Traumatologia. 2006: 109-125.

[7] Bertucci FN, Tedrus GMAS. Infecções em próteses ortopédicas: revisão da literatura. Anais do XV Encontro de Iniciação Científica da PUC-Campinas Campinas; 2010.

[8] Freitas F, Virgolino M, Ribeiro C. Infecção de prótese articular da anca e joelho. Revista Portuguesa de Ortopedia e Traumatologia. 2013: 165-172.

[9] Garrido-Gómez J, Arrabal-Polo MA, Girón-Prieto MS, et al. Descriptive analysis of the economic costs of periprosthetic joint infection of the knee for the public health system of Andalusia. J Arthroplasty. 2013;28:1057-1060.

[10] Taylor EN, Webster TJ. The use of superparamagnetic nanoparticles for prosthetic biofilm prevention. Int J Nanomed. 2009;4:145-152.

[11] Moura J, Baylina P, Moreira P. Exploring the real costs of healthcare-associated infections: an international review. Int J Healthcare Manage. 2017: 1-8. doi:10. 1080/20479700.2017.1330729.

[12] Veillard J, Guisset A-L, Garcia-Barbero M. Selection of indicators for hospital performance measurement. A Report on the 3rd and 4th WHO Workshop Barcelona, Spain, June and September: 2003.

[13] WHO. Measuring hospital performance to improve the quality of care in Europe: a need for clarifying the concepts and defining the main dimension. Report on a WHO Workshop Barcelona, Spain. 2003: 10-11.

[14] Tumbarello M, Repetto E, Trecarichi E, et al. Multidrug-resistant Pseudomonas aeruginosa bloodstream infections: risk factors and mortality. Epidemiol Infect. 2011;139:1740-1749.

[15] Plowman R. The socioeconomic burden of hospital acquired infection. Euro Surveill. 2000;5:49-50.

[16] Bôas P, Ruiz T. Ocorrência de infecção hospitalar em idosos internados em hospital universitário. Rev Saúde Pública. 2004;38:372-378.

[17] Kirkland KB, Briggs JP, Trivette SL, et al. The impact of surgical-site infections in the 1990s: attributable mortality, excess length of hospitalization, and extra costs. Infect Control Hosp Epidemiol. 1999;20:725-730.

[18] Rocha LÁ. Vigilancia de la infección nosocomial en la UCI. Medicina Intensiva. 2002;26:61-63. 